729 磁界の周期的時間変動を受ける導体円柱の動的電磁熱弾性解析

$$
\text { （一般化平面ひずみの場合） }
$$

\title{
Dynamic Magnetothermoelastic Behavior of a Conducting Solid Circular Cylinder Subjected to Cyclic Variation of Magnetic Field (In the case of Generalized Plane Strain State )
}

\author{
○学 樋口理宏（阪府大院） 正 河村隆介（阪府大院） \\ 正 谷川義信（阪府大院）
}

Masahiro HIGUCHI, Graduate School of Engineering, Osaka Prefecture University

Ryuusuke KAWAMURA, Graduate School of Engineering, Osaka Prefecture University, 1-1, Gakuen-cho, Sakai, Osaka Yoshinobu TANIGAWA, Graduate School of Engineering, Osaka Prefecture University

\begin{abstract}
In the present article, a theoretical treatment of dynamic behaviors for magnetothermoelastic stresses and deformation is dealt with in a conducting solid circular cylinder subjected to both internal heat generation due to eddy current loss and Lorentz force by cyclic time variation of magnetic field. Assuming that uniform magnetic field whose intensity varies sinusoidally with time acts on the cylinder in the direction parallel to its surface, plane axisymmetrical magnetic field and the associated eddy current in the cylinder due to electromagnetic induction have been formulated based on the theory of quasi-stationary electromagnetic field. Thereafter, dynamic behaviors of magnetothermoelastic stresses and deformation in a conducting solid cylinder, which are subjected to both plane axisymmetrical temperature change due to eddy current loss and Lorentz force, have been analyzed under the plane strain condition or generalized plane strain condition. Comparing numerical results of dynamic behaviors for magnetothermoelastic stresses and deformation in the cylinder with those of quasi-static one, an effect of frequency in cyclic time variation of magnetic field has been examined.
\end{abstract}

Key words: Magnetothermoelasticity , Circular cylinder, Generalized plane strain condition, Dynamic behavior, Eddy current loss

\section{1 緒 言}

本研究は，導体無限円柱が磁界の周期的時間変動を受ける 際の渦電流損による内部発熱とローレンツカによる電磁熱 応力と変形の動的挙動の理論解析を取り扱つたものである. まず, 強さが正弦的に時間変化する一様な磁界が円柱の表 面に平行に作用する場合を想定し，円柱内部の平面軸対称 な磁界と電磁誘導法則による渦電流を準定常電磁理論に基 づいて定式化した. そして, 渦電流損による平面軸対称な温 度変化とローレンツカを受ける導体円柱の電磁熱応力と変 形の準静的および動的挙動を一般化平面ひずみ条件あるい は平面ひずみ条件下で解析した。 また，円柱内部の電磁熱 応力之変形の動的挙動の数值結果と準静的挙動を比較して, 磁界の周期的時間変動の周波数の効果を検討した.

\section{2 渦電流解析}
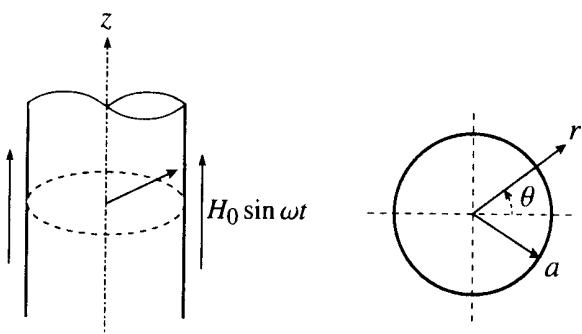

Fig. 1 Analytical model and conditions

Fig.1 に示すように導体無限円柱の表面に, 時刻 $t=0$ の 瞬間から強さ $H_{0}$, 角周波数 $\omega$ で正弦的に時間変化する一様 な磁界が，円柱の表面に平行に作用する際の冈柱内部に生じ る磁界を考光る。

このとき磁界は導体内で平面軸対称であり, 軸方向成分 $H_{z}$ のみを持つ. 導体円柱内の磁界の強さ $H_{z}$ に関する基礎 方程式, 初期条件, 境界条件を無次元表示すると次式のよう に表される(1)

$$
\begin{array}{ll}
\frac{1}{\bar{r}} \frac{\partial}{\partial \bar{r}}\left(\bar{r} \frac{\partial \bar{H}_{z}}{\partial \bar{r}}\right)=\bar{\mu} \bar{\sigma} \frac{\partial \bar{H}_{z}}{\partial \tau} \\
\tau=0 \quad ; \quad \bar{H}_{z}(\bar{r}, 0)=0 \\
\bar{r}=1 \quad ; \quad \bar{H}_{z}(1, \tau)=\sin \bar{\omega} \tau
\end{array}
$$

ただし, $\bar{\mu}, \bar{\sigma}$ は導体の透磁率および電気伝導率の無次元量 を表す。
式 (1) (3) をラプラス変換法を用いて解くと, 磁界 $\bar{H}_{z}$ が 得られ, 電磁誘導の法則から渦電流密度 $\bar{J}_{\theta}$ が得られる.

$$
\begin{aligned}
& \bar{J}_{\theta}(\bar{r}, \tau)=\sum_{m=1}^{\infty} e^{-\bar{\delta}^{2} k_{m}^{2} \bar{\nu} \tau} \frac{2 \bar{\delta}^{2} k_{m}^{2}}{\left(\bar{\delta}^{4} k_{m}^{4}+1\right) J_{1}\left(k_{m}\right)} \mathbf{J}_{1}\left(k_{m} \bar{r}\right)
\end{aligned}
$$

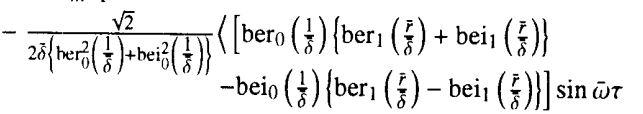

$$
\begin{aligned}
& \text { - }\left[\operatorname{ber}_{0}\left(\frac{1}{\delta}\right)\left\{\operatorname{ber}_{1}\left(\frac{\bar{F}}{\delta}\right)-\operatorname{bei}_{1}\left(\frac{\bar{r}}{\delta}\right)\right\}\right. \\
& \left.\left.+\operatorname{bei}_{0}\left(\frac{1}{\delta}\right)\left\{\operatorname{ber}_{1}\left(\frac{F}{\delta}\right)+\operatorname{bei}_{1}\left(\frac{\tilde{F}}{\delta}\right)\right\}\right] \cos \bar{\omega} \tau\right\rangle
\end{aligned}
$$

ただし, $k_{m}$ は

$$
\mathrm{J}_{0}(k)=0
$$

を満たす $m$ 番目の正根であり, $\bar{\delta}$ は次式で定義される表皮 深さの無次元量である.

$$
\bar{\delta}=1 / \sqrt{\bar{\mu} \bar{\sigma} \bar{\omega}}
$$

また, $\mathrm{J}_{n}(\cdot)$ は $n$ 次の第一種ベッセル関数, $\operatorname{ber}_{n}(\cdot), \operatorname{bei}_{n}(\cdot)$ は $n$ 次の第一種ケルビン関数である.

渦電流損による内部発熱と, 渦電流が磁界から受けるロー レンツカはそれぞれ次のように表される。

$$
\begin{aligned}
& \bar{w}(\bar{r}, \tau)=\frac{\bar{J}_{\theta}^{2}}{\bar{\sigma}} \\
& \bar{f}_{r}(\bar{r}, \tau)=\bar{\mu} \bar{J}_{\theta} \bar{H}_{z}=-\frac{\bar{\mu}}{2} \frac{\partial}{\partial \bar{r}}\left(\bar{H}_{z}^{2}\right)
\end{aligned}
$$

\section{3 非定常熱伝導解析}

初期温度が零度で温度零度の外界と無次元相対熱伝達率 $\bar{h}$ で熱伝達がある円柱において, 単位体積単位時間当たり $\bar{w}(\bar{r}, \tau)$ の内部発熱が生ずるときの温度変化を考える.

このとき, 内部発熱を考慮した非定常熱伝導方程式, 初期 条件, 境界条件を無次元表示すると次式のように表される.

$$
\begin{array}{ll}
\bar{C} \bar{\gamma} \frac{\partial \bar{T}}{\partial \tau}=\bar{\lambda}\left\{\frac{1}{\bar{r}} \frac{\partial}{\partial \bar{r}}\left(\bar{r} \frac{\partial \bar{T}}{\partial \bar{r}}\right)\right\}+\bar{w} \\
\tau=0 \quad ; \quad \bar{T}=0 \\
\bar{r}=1 \quad ; \quad \frac{\partial \bar{T}}{\partial \bar{r}}+\bar{h} \bar{T}=0
\end{array}
$$

ただし, $\bar{T}$ は無次元温度変化であり, $\bar{C}, \bar{\gamma}, \bar{\lambda}$ は比熱, 密度 および熱伝導率の無次元量を表す.

式 (9)〜(11)の方程式を解くにあたり，次式で定義される グリーン関数 $\bar{G}_{1}$ を導入する.

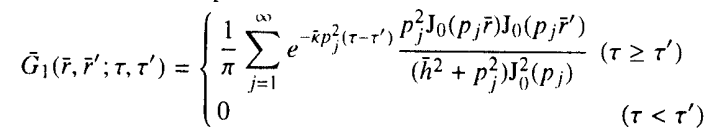


ただし, $\overline{\boldsymbol{K}}$ は温度伝導率の無次元量, $p_{j}$ は

$$
-p \mathbf{J}_{1}(p)+\bar{h} \mathrm{~J}_{0}(p)=0
$$

を満たす $j$ 番目の正根である.

式 (12)のグリーン関数を用いると, 温度変化が次式で表 される。

$$
\begin{aligned}
\bar{T}(\bar{r}, \tau) & =\int_{0}^{\tau}\left\{\int_{0}^{1} \frac{1}{\bar{C} \bar{\gamma}} \bar{G}_{1}\left(\bar{r}, \bar{r}^{\prime} ; \tau, \tau^{\prime}\right) \bar{w}\left(\bar{r}^{\prime}, \tau^{\prime}\right) 2 \pi \bar{r}^{\prime} d \bar{r}^{\prime}\right\} d \tau^{\prime} \\
& =\sum_{j=1}^{\infty} A_{j}(\tau) p_{j} \mathrm{~J}_{0}\left(p_{j} \vec{r}\right)
\end{aligned}
$$

\section{4 動的電磁熱弾性解析}

\section{1 基礎方程式}

平面軸対称な温度変化 $T$ とローレンツ力 $f_{r}$ を受ける際の 電磁熱弾性問題を一般化平面ひずみ条件あるいは平面ひず み条件の下で定式化する.

円柱表面に外力が作用しない場合を想定し, 時刻 $\tau=0$ で 円柱が静止しているものとする。このとき，一般化平面ひず み条件における運動方程式, 初期条件, 境界条件の無次元表 示式は次式で与えられる。

$$
\begin{aligned}
& \frac{\partial}{\partial \bar{r}}\left\{\frac{1}{\bar{r}} \frac{\partial\left(\bar{r} \bar{u}_{r}\right)}{\partial \bar{r}}\right\}=\frac{1}{\bar{C}_{L}^{2}} \frac{\partial^{2} \bar{u}_{r}}{\partial \tau^{2}}+\left(1+v^{*}\right) \bar{\alpha}^{*} \frac{\partial \bar{T}}{\partial \bar{r}}+\frac{1-v^{* 2}}{\bar{E}^{*}} \frac{\bar{\mu}}{2} \frac{\partial}{\partial \bar{r}}\left(\bar{H}_{z}^{2}\right) \\
& \tau=0 ; \quad \bar{u}_{r}=\frac{\partial \bar{u}_{r}}{\partial \tau}=0 \\
& \bar{r}=1 \quad ; \quad \frac{\partial \bar{u}_{r}}{\partial \bar{r}}+v^{*} \frac{\bar{u}_{r}}{\bar{r}}-\left(1+v^{*}\right) \bar{\alpha}^{*} \bar{T}+v^{*} C_{z}=0
\end{aligned}
$$

ただし, $\bar{u}_{r}$ は半径方向の変位の無次元量, $C_{z}$ は軸方向の一 様ひずみであり, $\bar{C}_{L}$ は次式で定義される膨張波速度の無次 元量である.

$$
\bar{C}_{L}=\sqrt{\bar{E}^{*} /\left(1-\nu^{* 2}\right) \bar{\gamma}}
$$

また

$$
\bar{E}^{*}=\bar{E} /\left(1-v^{2}\right), \quad v^{*}=v /(1-v), \quad \bar{\alpha}^{*}=(1+v) \bar{\alpha}
$$

と表され, $\bar{E}$ は縦弾性係数の無次元量, $v$ はポアソン比, $\bar{\alpha}$ は線膨張係数の無次元量である.

\section{2 準静的解析}

変位 $\bar{u}_{r}$ を次式のように準静的項 $\bar{u}_{r}^{(1)}$ と動的項 $\bar{u}_{r}^{(2)}$ の和と して表す。

$$
\bar{u}_{r}=\tilde{u}_{r}^{(1)}+\ddot{u}_{r}^{(2)}
$$

ただし， $\bar{u}_{r}^{(1)}$ は式 (15) の慣性項を無視した次式の釣り合い 方程式と初期条件, 境界条件を満たすものとする.

$$
\begin{aligned}
& \frac{\partial}{\partial \bar{r}}\left\{\frac{1}{\bar{r}} \frac{\partial\left(\bar{r} \bar{u}_{r}^{(1)}\right)}{\partial \bar{r}}\right\}=\left(1+v^{*}\right) \bar{\alpha}^{*} \frac{\partial \bar{T}}{\partial \bar{r}}+\frac{1-v^{* 2}}{\bar{E}^{*}} \frac{\bar{\mu}}{2} \frac{\partial}{\partial \bar{r}}\left(\bar{H}_{z}^{2}\right) \\
& \tau=0 ; \quad \bar{u}_{r}^{(1)}=\frac{\partial \bar{u}_{r}^{(1)}}{\partial \tau}=0 \\
& \bar{r}=1 ; \quad \frac{\partial \bar{u}_{r}^{(1)}}{\partial \bar{r}}+v^{*} \frac{\bar{u}_{r}^{(1)}}{\bar{r}}-\left(1+v^{*}\right) \bar{\alpha}^{*} \bar{T}+v^{*} C_{z}=0
\end{aligned}
$$

式 $(21) \sim(23)$ より変位の準静的項 $\bar{u}_{r}^{(1)}$ は次式のように表 される。

$$
\begin{aligned}
& \bar{u}_{r}^{(1)}=\bar{\alpha}^{*} \sum_{j=1}^{\infty} A_{j}(\tau)\left\{\left(1+v^{*}\right) \mathrm{J}_{1}\left(p_{j} \bar{r}\right)+\left(1-v^{*}\right) \mathrm{J}_{1}\left(p_{j}\right) \bar{r}\right\} \\
& +\frac{1-v^{*}}{\bar{E}^{*}} \frac{\bar{\mu}}{2}\left\{\left(1+v^{*}\right) F_{L}(\bar{r}, \tau)+\left(1-v^{*}\right) F_{L}(1, \tau) \bar{r}-\bar{r} \bar{H}_{z}^{2}(1, \tau)\right\} \\
& -\frac{v^{*}}{1+v^{*}} C_{z} \bar{r}
\end{aligned}
$$

軸方向ひずみ $C_{z}$ は拘束条件により決定する，軸方向に拘 束されない場合は, 次式の軸方向の合力が零となるための条 件により決定される.

$$
\int_{0}^{1} \bar{\sigma}_{z z}^{(1)} 2 \pi \bar{r} d \bar{r}=0
$$

また，軸方向に完全拘束される場合は $C_{z}=0$ となる.

\section{3 動的解析}

解析の一例として, 平面ひずみ条件 $C_{z}=0$ の場合を考 える.

式 (20) を式 (15)〜 (17) に代入すると変位の動的項 $\bar{u}_{r}^{(2)}$ に 関する方程式系が次のように得られる.

$$
\begin{aligned}
& \frac{\partial}{\partial \bar{r}}\left\{\frac{1}{\bar{r}} \frac{\partial\left(\bar{r} \bar{u}_{r}^{(2)}\right)}{\partial \bar{r}}\right\}=\frac{1}{\bar{C}_{L}^{2}} \frac{\partial^{2} \bar{u}_{r}^{(2)}}{\partial \tau^{2}}+\frac{1}{\bar{C}_{L}^{2}} \frac{\partial^{2} \bar{u}_{r}^{(1)}}{\partial \tau^{2}} \\
& \tau=0 \quad ; \quad \bar{u}_{r}^{(2)}=\frac{\partial \bar{u}_{r}^{(2)}}{\partial \tau}=0 \\
& \bar{r}=1 \quad ; \quad \frac{\partial \bar{u}_{r}^{(2)}}{\partial \bar{r}}+v^{*} \frac{\bar{u}_{r}^{(2)}}{\bar{r}}=0
\end{aligned}
$$

式 (26)〜 (28) の方程式を解くにあたり, 次式で定義され るグリーン関数 $\bar{G}_{2}$ を導入する.

$\bar{G}_{2}\left(\bar{r}, \bar{r}^{\prime} ; \tau, \tau^{\prime}\right)=\left\{\begin{array}{lr}\frac{1}{\pi} \sum_{i=1}^{\infty} \frac{\sin \omega_{i}\left(\tau-\tau^{\prime}\right)}{\omega_{i}} \frac{\eta_{i}^{2} \mathrm{~J}_{1}\left(\eta_{i} \bar{r}\right) \mathrm{J}_{1}\left(\eta_{i} \bar{r}^{\prime}\right)}{\left\{\left(1+\nu^{*}\right) \eta_{i}^{2}-1\right\} \mathrm{J}_{1}^{2}\left(\eta_{i}\right)} \\ \left(\tau \geq \tau^{\prime}\right) \\ 0 & \left(\tau<\tau^{\prime}\right)\end{array}\right.$

ただし， $\eta_{i}$ は

$$
\eta \mathrm{J}_{0}(\eta)-\left(1-v^{*}\right) \mathbf{J}_{1}(\eta)=0
$$

を満たす $i$ 番目の正根であり， $\omega_{i}$ は次式により定義される 固有角周波数の無次元量である.

$$
\omega_{i}=\bar{C}_{L} \eta_{i}
$$

式 (29)のグリーン関数を用いると, 変位の動的項 $\bar{u}_{r}^{(2)}$ は 次式で表される.

$$
\begin{aligned}
& \bar{u}_{r}^{(2)}=\sum_{i=1}^{\infty} \frac{2 \eta_{i}^{2}}{\left\{\left(1+v^{*}\right) \eta_{i}^{2}-1\right\} \mathrm{J}_{1}^{2}\left(\eta_{i}\right)} \mathrm{J}_{1}\left(\eta_{i} \bar{r}\right) \\
& \times \int_{0}^{1} \bar{r}^{\prime} \mathrm{J}_{1}\left(\eta_{i} \bar{r}^{\prime}\right)\left\{-\bar{u}_{r}^{(1)}+\omega_{i} \int_{0}^{\tau} \sin \omega_{i}\left(\tau-\tau^{\prime}\right) \bar{u}_{r}^{(1)} d \tau^{\prime}\right\} d \bar{r}^{\prime}
\end{aligned}
$$

係数 $A_{j}(\tau), F_{L}(\bar{r}, \tau)$ ならびに応力成分，ひずみ成分の詳 細については紙面の制約上省略する.

\section{5 数値計算例}

計算結果の一例として，アルミニウム合金からなる半径 $a=0.01[\mathrm{~m}]$ の円柱に, 強さ $H_{0}=10^{7} / 4 \pi[\mathrm{A} / \mathrm{m}]$, 角周波数 $\omega=2 \pi \times 600[\mathrm{rad} / \mathrm{sec}]$ の磁界の周期的時間変動を与えた際 の, 温度変化の半径方向の分布を Fig. 2 に, 半径方向熱応力 の準静的項の半径方向分布を Fig.3にそれぞれ示す.

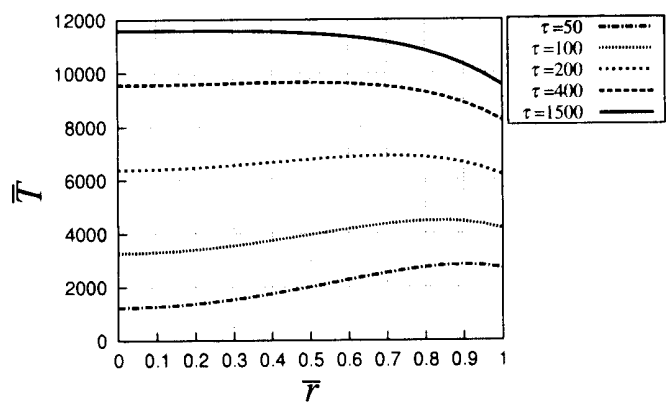

Fig. 2 Radial variation of temperature change $\bar{T}$

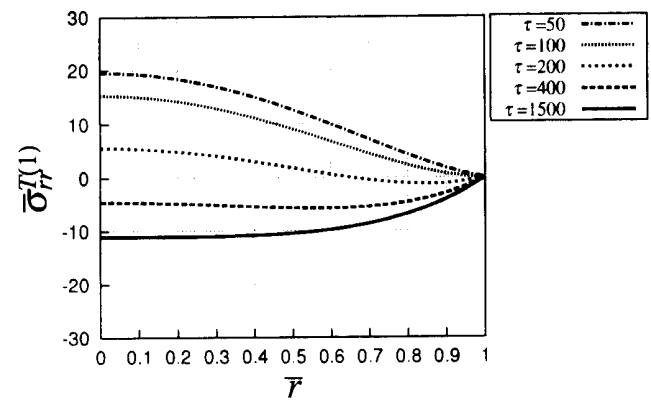

Fig. 3 Radial variation of thermal stress $\bar{\sigma}_{r r}^{T(1)}$

\section{参考文献}

(1) 樋口 · 河村 • 谷川, 機構論, No.034-1, (2003), 2-57. 